\title{
Pellon hintaan vaikuttavat tekijät Suomessa ja Uudessa-Seelannissa
}

\author{
Sami Myyrä ${ }^{1)}$ \\ ${ }^{1)}$ MTT taloustutkimus, Luutnantintie 1300410 Helsinki, sami.myyra@mtt.fi
}

\section{Tiivistelmä}

Perinteisesti pellon hintaa on mallinnettu nettotuottojen nykyarvoon perustuvilla menetelmillä. Niissä maasta tulevaisuudessa saatavat tuotot on diskontattu nykyhetkeen. Diskontattua tuottojen nykyarvoa on voitu verrata pellon markkinahintoihin. Hedonisilla hintamalleilla on puolestaan pyritty selittämään pellon markkinahintoja pellon ominaisuuksilla. Mallien avulla ei ole kuitenkaan pystytty selittämään maatalouden alentuneen kannattavuuden ja nousseiden pellon hintojen epäsuhtaista kehitystä. Tämä johtunee siitä, että menetelmät ovat toistaiseksi keskittyneet lähinnä pellon maataloustuotannollisiin ominaisuuksiin ja tuottoarvoon.

Pellon omistus on viime vuosina siirtynyt yhä enenevässä määrin maataloustuotannon suhteen passiivisille omistajille. Noin 40 \% pelloista on vuokramiesten viljelyssä. Pellosta vuokraamalla saatava tuotto ei kuitenkaan selitä pellon omistamishalukkuutta, sillä vuokratuotto on hyvin maltillinen, joskin lähes varma. Vain 0,2 - 0,3 \% pelloista vaihtaa vuosittain omistajaa vapailla markkinoilla puhtaina peltomaakauppoina.

Latentteja maanomistukseen liittyviä arvoja tai asenteita ei voida suoraan kytkeä toteutuneisiin kauppahintoihin, kuten on ollut mahdollista pellon laatua kuvaavien muuttujien suhteen. Tässä tutkimuksessa keskitytäänkin selvittämään yhteiskunnan yleisen talouskehityksen sekä koko maataloustoimialan tuloksen yhteyttä pellon markkinahintoihin (H). Näin pystytään kytkemään taloudellisen kehityksen myötä vahvistuva kansalaisten ostovoiman kasvu, maanomistukseen liittyvät arvot ja pellon hintamuutokset toisiinsa. Yleistä talouskehitystä mitataan bruttokansantuotteella (BKT) ja maataloustoimialan tulosta maataloustulolla (MT). Pellon hintoja selittävien muuttujien BKT ja MT sekä pellon hinnan keskinäinen yhteisintegroituvuus on välttämätön mutta eri riittävä edellytys analyysille. Yhteisintegroituvuus ei vielä kerro sitä, miten yhteisintegroituvuusmallin parametrit muuttuvat (konvergoituvat) yli ajan.

Keskeisimpänä tutkimushypoteesina on, että muualta yhteiskunnasta tulevat muutokset vaikuttavat pellon hintoihin. Tämän vaikutuksen voidaan olettaa muuttuvan ajan suhteen. Tutkimusaineistona käytetään aikasarjoja pellon hinnan, maataloustulon ja bruttokansantuotteen kehityksestä. Aineistoon poimittiin kahden toisistaan täysin poikkeavan maatalousmaan aikasarjat vuosilta 1981 - 2005. Uudessa-Seelannissa maatalouden tukijärjestelmästä luovuttiin 1984. Suomessa maatalouden tukijärjestelmän rooli maatalouden kannattavuuteen ja ehkä myös pellon hintoihin vaikuttavana tekijänä muuttui olennaisesti vuonna 1995.

Tulokset osoittavat, että 100 \% nousu pellon hinta / maataloustulo suhteessa nostaa Suomessa pellon hinta / bruttokansantuote suhdetta vain $26 \%$. Uudessa-Seelannissa pellon hinnat ovat olleet kiinteämmin sidoksissa maatalouden kannattavuuteen. Esimerkiksi $100 \%$ nousu maataloustulo / bruttokansantuote suhteessa johti Uudessa-Seelannissa keskimäärin 42 \% nousuun pellon hinta / bruttokansantuote suhteessa. Tulokset vahvistavat käsityksen siitä, että Suomessa maatalouden kannattavuuteen vaikuttavasta tukijärjestelmästä on vaikea löytää instrumentteja, joilla voitaisiin ohjata pellon hintakehitystä.

Aineisto antoi myös viitteitä siitä, ettei EU jäsenyydellä ollutkaan shokkivaikutusta lukuunottamatta kovin suurta vaikutusta pellon hintavaihteluita selittävien tekijöiden (bruttokansantuote ja maataloustulo) suhteeseen. Muualta yhteiskunnasta tulevat vaikutukset - maanomistajien arvot ja asenteet - ovat olleet jo ennen EU aikaa keskeisesti vaikuttamassa pellon hintoihin. Uusiseelantilaisessa aineistossa maataloustulon merkitys pellon hintaan vaikuttavana tekijänä laski huomattavasti 1990 luvun alusta. Tulosta pidettiin Uudessa-Seelannissa huolestuttava, sillä maatalouden keskeisimmän tuotannontekijän hinta ja maatalouden kannattavuuden välinen yhteys on katkeamassa.

Asiasanat: Pellon hinta, BKT, maataloustulo 


\section{Johdanto}

Pellon hinta on yksi keskeisimmistä maataloustuotantoon, pellon käyttöön ja tuotannon kannattavuuteen vaikuttavista tekijöistä. Pellon hinta välittää informaatiota tuotannon kannattavuudesta ja tulevaisuuden odotuksista. Toisaalta pellon hinta vaikuttaa olennaisesti tuotannosta luopuvien ja tuotantoa jatkavien väliseen tulonjakoon.

Perinteisesti pellon hintaa on mallinnettu nettotuottojen nykyarvoon perustuvilla menetelmillä. Niissä maasta tulevaisuudessa saatavat tuotot on diskontattu nykyhetkeen. Diskontattua tuottojen nykyarvoa on voitu verrata pellon markkinahintoihin (Ylätalo, 1992; Peltola, 1997). Hedonisilla hintamalleilla on puolestaan pyritty selittämään pellon markkinahintoja pellon ominaisuuksilla (Pyykkönen, 2006; Peltola, 2006). Malleilla ei ole kuitenkaan pystytty selittämään maatalouden alentuneen kannattavuuden ja nousseiden pellon hintojen epäsuhtaista kehitystä. Tämä johtunee siitä, että menetelmät ovat toistaiseksi keskittyneet lähinnä pellon maataloustuotannollisiin ominaisuuksiin ja tuottoarvoon.

Tässä artikkelissa verrataan maatalouden yleisen kannattavuuden ja yleisen talouskehityksen yhteyttä pellon hintakehitykseen (H). Maatalouden kannattavuutta mitataan maataloustulolla (MT) ja yleistä talouskehitystä bruttokansantuotteella (BKT). Menetelmä perustuu aikasarjojen konvergoitumisen tarkasteluun.

Tätä menetelmää ei ole aikaisemmin käytetty pellon hintakehityksen selittämiseen. Uusien pellon hintakehitystä selittävien menetelmien etsiminen on tärkeää, sillä aikaisemmilla menetelmillä ei ole pystytty selittämään kaikkea pellon hinnoissa esiintyvää vaihtelua.

Erityisenä mielenkiinnon kohteena viimeaikaisessa pellon hintoja koskevassa tutkimuksessa on ollut tukien pääomittuminen pellon hintoihin (Pyykkönen, 2006; Goodwin ym. 2003). Tulokset ovat osittain ristiriitaisia, eikä yksiselitteisiä vastauksia keskeiseen luopuvien ja jatkavien maatalousyrittäjien väliseen tulonjakokysymykseen ole löydetty. Tämä johtuu osittain siitä, että pellon omistuksen ja hallintaan liittyvä kulttuuri, arvot ja asenteet vaihtelevat olennaisesti maanosien ja maiden välillä. Esimerkiksi UudessaSeelannissa viljelijät ostavat ja myyvät kokonaisia maatiloja ilman ylitsepääsemättömiä tunnesiteitä. Suomessa on vahva sukutila kulttuuri, jossa pellon myyminen ei ole pelkästään taloudellinen kysymys. Erilaisesta maanomistuskulttuurista johtuvat taloudelliset seuraukset erityisesti pellon hintoihin voivat olla merkittäviä

Tässä paperissa tarkastellaan sitä, seuraako pellon hinta pikemmin maatalouden kannattavuuskehitystä, kuin yleistä talouskehitystä ja sitä onko tässä kehityksessä tapahtunut ajan myötä muutosta. Havainnot voidaan kytkeä esimerkiksi maatalouden tukijärjestelmässä tapahtuneisiin muutoksiin. Tutkimuksen tavoite kiteytetään kahteen hypoteesiin:

1: Yleisessä talouskehityksessä tapahtuneet muutokset vaikuttavat pellon hintoihin ja tämä vaikutus on voinut muuttua ajan myötä.

2: Maatalouden kannattavuudessa tapahtuneet muutokset vaikuttavat pellon hintoihin ja tämä vaikutus on voinut muuttua ajan myötä.

\section{Aineisto ja menetelmät}

\section{Aineisto}

Tutkimusaineistona käytetään aikasarjoja pellon hinnan, maataloustulon ja bruttokansantuotteen kehityksestä vuosina 1981 - 2005. Aikasarja analyysiin aineisto on hyvin rajallinen, sillä pellon hintoja ei ole tarkasteltu viikoittain eikä edes kuukausittain. Tämä johtuu lähinnä siitä, että tilastointikelpoisten ja puhtaiden peltomaakauppojen määrä on etenkin suomessa erittäin pieni. Aineistoa rajoittaa myös se, että Uudessa-Seelannissa bruttokansantuotteen laskentaa uudistettiin 1987 niin merkittävästi, etteivät aikaisempi ja nykyinen aikasarja ole keskenään vertailukelpoisia.

Pyykkönen (2006) on kuvannut tilastointikelpoisen puhtaan peltomaakaupan tunnuspiirteet. Hintaaineisto kootaan Maanmittauslaitoksen toimesta ja se julkaistaan vuosittain ilmestyvässä Kiinteistöjen kauppahintatilastossa. Valuation New Zealand kokoaa Uuden - Seelannin hintatiedot, jotka julkaistaan kuuden kuukauden välein julkaisussa "Rural and urban proberty sales summaries". Pellon hinnat on julkaistu tilastoissa käypähintaisina ja ne on muutettu reaalihintaisiksi muiden aikasarjojen tapaan kuluttaja- 
hintaindeksillä. Aikasarjat on esitetty vuoden 2005 euroina ja Uuden - Seelannin dollareina.

Pellon hintasarjoja on täydennetty bruttokansantuote (BKT) ja maataloustulo (MT) tiedoilla. BKT sarjat perustuvat Tilastokeskuksen ${ }^{1}$ ja Data Stream Network of New Zealandinin ${ }^{2}$ julkaisemiin tietoihin. Maataloustuloa koskevat tiedot perustuvat MTT taloustutkimuksen kokonaislaskelmaan esim. (Niemi \& Ahlstedt, 2006) ja Statistics New Zealand ${ }^{3}$ tietoihin (Kuva 1). Analyysia varten aineisto on muunnettu logaritmi muotoon.

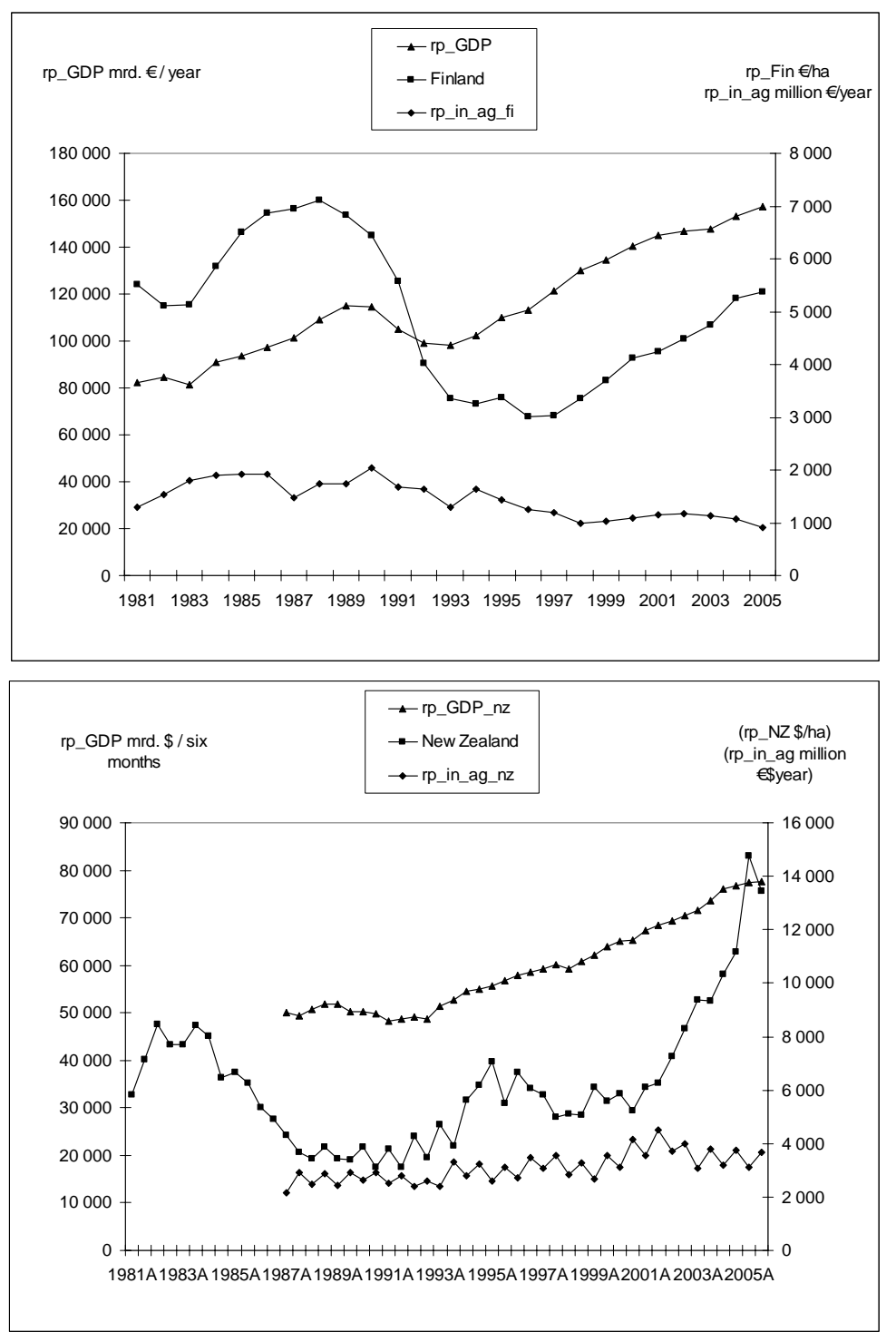

Kuva 1. Vasemmalla pystyakselilla reaalihintainen BKT (RP_GDP) miljoonina € ja NZ\$. Oikealla pystyakselilla reaalihintaiset pellon hinnat Suomessa (Finland) ja Uudessa-Seelannissa (New Zealand) €/ha ja NZ\$/ha, sekä aggregoitu maataloustulo miljoonaa $€$ (RP_IN_AG). Kaikki hinnat vuoden 2005 euroissa ja NZ dollareissa. Suomea koskeva aineisto on vuosittaista, kun taas Uuden-Seelannin aineisto on puolivuosittaista.

\section{Menetelmät}

Taloudellisilla aikasarjoilla on usein ominaisuuksia jotka pitää ottaa huomioon, jotta vältytään teknisiltä

\footnotetext{
${ }^{1}$ http://www.stat.fi/tup/suoluk/suoluk_kansantalous.html

2 http://www.thomson.com/content/financial/brand_overviews/Datastream_Advance

3 Sähköposti Lynne Mackie 31.1.2007
} 
ongelmilta (Engle ja Granger 1987). Tässä tapauksessa tarkastelun kohteena olevilta logaritmimuotoon muunnetuilta aikasarjoilta, pellon hinnasta, BKT:sta ja MT:sta saattaa puuttua vakiovarianssi. Sarjat siis loittonisivat loputtomasti toisistaan, eivätkä analyysin perusoletukset täyttyisi. Vakiovarianssiuden eli stationaarisuuden oletus voidaan ohittaa, jos on löydettävissä sarjojen dynamiikkaa kuvaava lineaarikombinaatio, jonka virhetermi on stationaarinen.

Tässä tutkimuksessa ei olla niinkään kiinnostuneita sarjojen dynamiikkaa kuvaavasta lineaarikombinaatiosta, lyhyen aikavälin virheenkorjausmallista ja pitkän aikavälin tasapainosta, vaan rakenteellisista muutoksista BKT:n ja MT:n vaikutuksessa pellon hintaan. Perinteinen aikasarjadynamiikkaa kuvaava lineaarikombinaatio ei pysty paljastamaan rakenteellisia muutoksia joten mallinnus poikkeaa olennaisesti Englen ja Grangerin (1987) esittämästä (Haldane ja Hall 1991). Mallinnuksen tavoitteena on tarkastella sitä miten aikasarjat seuraavat toisiaan.

Aineiston yhteisintegroituvuus voidaan varmistaa muuntamalla kaikki aineiston aikasarjat stationaarisiksi. Aineisto muunnettiin 1. differenssi muotoon. Tehdyt stationaarisuustestit vahvistivat menettelyn välttämättömyyden ja riittävyyden.

Aikasarjojen konvergoitumisen testaamiseksi Hall ym. (1992) kehittivät menetelmän, jolla kahden aikasarjan erotusta voidaan verrata toisen kyseessä olevan aikasarjan ja kolmannen aikasarjan erotukseen. Malli voidaan kirjoittaa muotoon:

$\left[X_{1}-X_{2}\right]_{(t)}=a_{(t)}+b_{(t)}\left[X_{1}-X_{3}\right]_{(t)}+e_{(t)}$

missä X1, X2, ja X3 ovat logaritmimuodossa olevia aikasarjoja. Hall ym. (1992) osoittivat, että jos $X_{1}$ ja $\mathrm{X}_{2}$ ovat konvergoituneet, niin $\mathrm{b}_{(\mathrm{t})}$ lähestyy nollaa. Tämä tarkoittaa sitä, että $\mathrm{X}_{1}$ on enimmäkseen, tai är̈ritapauksessa $[\mathrm{b}(\mathrm{t})=0]$ kokonaan yhteydessä muutoksiin $\mathrm{X}_{2}$ :ssa. Jos $[\mathrm{b}(\mathrm{t})=0]$ malli supistuu muotoon

$\left[X_{1}-X_{2}\right]_{(t)}=a_{(t)}+e_{(t)}$

ja $\mathrm{a}_{(\mathrm{t})}$ kuvaa sarjojen keskimääräistä erotusta $\mathrm{e}_{(\mathrm{t})}$ :n ollessa stokastista vaihtelua.

Ajan suhteen muuttuvat parametrit $\mathrm{a}_{(\mathrm{t})}$ ja $\mathrm{b}_{(\mathrm{t})}$ voidaan estimoida Kalman filtteri menetelmällä (Hall ym. 1992). Perusperiaatteeltaan Kalman filtteri menetelmä muistuttaa rekursiivista regressiomallia, jossa parametriestimaatit lasketaan aina uudestaan, kun uusi havainto saadaan. Tavoitteena on siis erottaa signaali mittausaineistosta heti kun se on mahdollista. Toisaalta mittausvirheet voidaan helposti erottaa aineistosta. Rekursiivisesta regressiomallista Kalman filtteri eroaa lähinnä siinä, että sen avulla voidaan tarkemmin määritellä aineistoon liittyviä viiverakenteita (Cuthertson et al., 1992; Harvey, 1981). Ennen yli ajan muuttuvien parametrien estimointia parametrien staattiset arvot voidaan selvittää pienimmän neliösumman menetelmällä (OLS).

\section{Sovellutus}

Aikasarjojen yhteisintegroituvuuden varmistamiseksi analyysiä ei voida tehdä absoluuttisilla hinnoilla vaan hintamuutoksilla. Aineisto on muunnettu logaritmimuotoon ja hypoteesin 2 mukainen malli voidaan nyt kirjoittaa muotoon:

$\left[\Delta H_{t}-\Delta B K T_{t}\right]_{(t)}=a_{(t)}+b_{(t)}\left[\Delta H_{t}-\Delta M T_{t}\right]_{(t)}+e_{(t)}$

Tässä tapauksessa $b_{(t)}$ tulkitaan niin, että vuotuiset muutokset $\mathrm{H} / \mathrm{BKT}$ suhteessa voidaan selittää $b_{(t)}: n$ suuruisilla muutoksilla H/MT -suhteessa. Jos $b_{(t)}$ on 0, muutokset H/MT -suhteessa eivät vaikuta $\mathrm{H} / \mathrm{BKT}$-suhteeseen ja pellon hinnat $(\mathrm{H})$ seuraavat täysin BKT:n muutoksia. Edelleen jos $\mathrm{b}_{(\mathrm{t})}=0$, muutokset $\mathrm{H} / \mathrm{BKT}$-suhteessa nähdään suoraan $\mathrm{a}_{(\mathrm{t})}$ : sta. Jos $\mathrm{b}_{(\mathrm{t})}=1$ niin hintamuutosten syiden tulkinta on vaikeaa. Tässä tapauksessa saataisiin kuitenkin näyttöä siitä, että BKT ja MT muuttuisivat ajan suhteen samaan tahtiin.

Jotta saataisiin laajemman käsityksen H/BKT ja H/MT suhteiden kehityksestä saamiseksi malli on muokattava hypoteesin 1 mukaiseksi:

$\left[\Delta H_{t}-\Delta B K T_{t}\right]_{(t)}=a_{(t)}+b_{(t)}\left[\Delta M T_{t}-\Delta B K T_{t}\right]_{(t)}+e_{(t)}$ 
Edelleen $b(t)=0$ tarkoittaa sitä, että pellon hinta $(\mathrm{H})$ seuraa bruttokansantuotteen $(\mathrm{BKT})$ muutoksia. Nyt $b(t)=1$ tarkoittaa sitä, että pellon hinnat $(H)$ seuraavat maataloustuloaggregaatin (MT) kehitystä. Yhtälön 4 tulkintaa voidaan edelleen selkeyttää jos vakio a on nolla.

\section{Tulokset ja tulosten tarkastelu}

\section{Keskimääräiset vaikutukset}

Estimointitulosten perusteella saadaan näyttöä siitä, että pellon hinnat $(\mathrm{H})$ eivät ole Suomessa vahvasti kytköksissä maataloustuloon (MT). Yhtälön 3 estimointitulokset osoittavat, että 100 \% nousu H/MT suhteessa nostaa H/BKT suhdetta vain 26 \% (Taulukko 1 / yhtäkö 3). Toisaalta yhtälö neljä osoittaa, että MT/BKT suhteen muutoksella ei ole vaikutusta H/BKT suhteeseen (Taulukko 1 / yhtälö 4). Suomalaisen pellonhinta-aineiston perusteella ei voida osoittaa, että pellon hintamuutokset konvergoituisivat niin maataloustuloaggregaatin muutosten kuin bruttokansantuotteen muutostenkaan kanssa.

Taulukko 1. Ajan suhteen kiinteät parametrit, Suomi.

\begin{tabular}{lcccc}
\hline \hline & parametri- & estimaatin & & \\
Yhtälö / Muuttuja & estimaatti & keskihajonta & t-arvo & p-arvo *) \\
\hline \hline 3 / a & 0,031 & 0,015 & $-2,015$ & 0,056 \\
3 / b & 0,260 & 0,097 & 2,668 & 0,014 \\
4 / a & $-0,027$ & 0,018 & $-1,453$ & 0,160 \\
4 / b & 0,021 & 0,128 & 0,169 & 0,867 \\
\hline \hline (3) R-squared & 0,244 & & & F-stat 7,121 \\
(4) R-squared & 0,001 & & F-stat 0,028 \\
\hline \hline
\end{tabular}

*) p-arvo kuvaa todennäköisyyttä sille, että parametriestimaatti on nolla.

Taulukko 2. Ajan suhteen kiinteät parametrit, Uusi-Seelanti.

\begin{tabular}{|c|c|c|c|c|}
\hline Yhtälö / Muuttuja & $\begin{array}{l}\text { parametri- } \\
\text { estimaatti }\end{array}$ & $\begin{array}{l}\text { estimaatin } \\
\text { keskihajonta }\end{array}$ & t-arvo & p-arvo *) \\
\hline $3 / a$ & 0,011 & 0,013 & 0,888 & 0,381 \\
\hline $3 / b$ & 0,447 & 0,040 & 11,050 & 0,000 \\
\hline $4 / a$ & 0,025 & 0,024 & 1,063 & 0,296 \\
\hline $4 / b$ & 0,423 & 0,126 & 3,349 & 0,002 \\
\hline (3) R-squared & 0,782 & F-statistic & & 122,098 \\
\hline (4) R-squared & 0,254 & F-statistic & & 11,219 \\
\hline
\end{tabular}

*) p-arvo kuvaa todennäköisyyttä sille, että parametriestimaatti on nolla.

Aineisto osoittaa, että pellon hinnat ovat Uudessa-Seelannissa huomattavasti selkeämmin konvergoituneet, eli kytköksissä maataloustuloaggregaattiin kuin Suomessa (Taulukko 2). Yhtälön 3 perusteella 100\% nousu H/MT suhteessa nostaa H/BKT suhdetta $45 \%$. Toisaalta yhtälö 4 osoittaa, että $100 \%$ :n nousu MT/BKT suhteessa nostaa H/MT suhdetta $42 \%$.

Uuden-Seelannin aineistossa yhtälössä 4, $\mathrm{a}_{(\mathrm{t})}=0$ eli termi voidaan tiputtaa pois. Yhtälö 4 voidaan uu- 
delleen kirjoittaa muotoon:

$$
\Delta H_{t}=b_{(t)} \Delta M T_{t}+\left(1-b_{(t)}\right) \Delta B K T_{t}+e_{(t)}
$$

Pellon hinnan muutos on tässä tapauksessa painotettu keskiarvo MT:n ja BKT:n muutoksista, painojen ollessa $\mathrm{MT}_{(\mathrm{t})}$ ja BKT(1-b $\left.\mathrm{b}_{(\mathrm{t})}\right)$. Painojen kehitystä voidaan tarkkailla estimoimalla ajan suhteen muuttuva $b_{(t)}$ yhtälöstä 6 .

\section{Ajan suhteen muuttuva vaikutus}

Ajan suhteen muuttuvien parametrien estimointi paljastaa eri tekijöiden pellon hintoihin antaman vaikutuksen muutoksen ajan suhteen. Suomalaisessa pellon hinta aineistossa H/MT suhteessa tapahtuneet muutokset ovat vaikuttaneet vain hyvin vähän H/BKT suhteeseen. Toisin sanoen maataloustulon muutokset eivät ole juurikaan olleet yhteydessä pellon hintamuutoksiin. Keskeisin tulos on kuitenkin se, ettei viimeisen kymmenen vuoden aikana Suomessa ole tapahtunut suurta rakenteellista muutosta MT:n ja BKT:n vaikutuksessa pellon hintoihin (Kuva 2).

Uuden-Seelannin aineisto mahdollisti analyysin tekemisen niin, että päästiin suoraan analysoimaan MT/BKT painojakaumaa pellon hintavaikutusten osalta (Kaava 6). Tulosten perusteella UudessaSeelannissa maataloustulolla ja bruttokansantuotteella on ollut lähes yhtä suuri vaikutus pellon hintakehitykseen. Olennaista on kuitenkin se, että maatalouden merkitys pellon hintoihin vaikuttavana tekijänä on laskenut (Kuva 2, oikealla) ja BKT:n vaikutus puolestaan noussut.
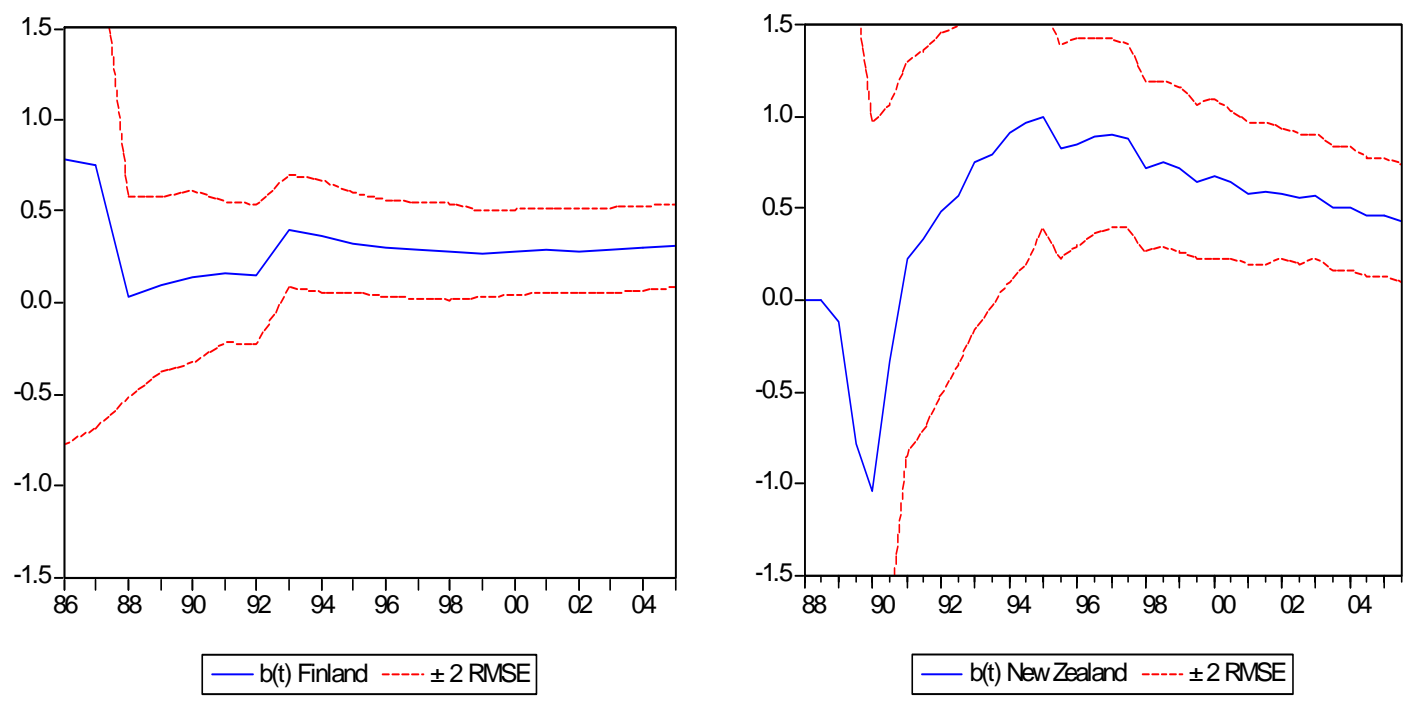

Kuva 2. Vasemmalla H/MT suhteen muutoksen vaikutus H/BKT suhteeseen Suomessa. Oikealla MT / BKT paino pellon hintakehitykseen Uudessa-Seelannissa.

\section{Johtopäätökset}

Suomalainen pellon hinta-aineisto antaa viitteitä siitä, että maataloustulon ja pellon hinnan välinen yhteys on Suomessa melko heikko. Tulos kertoo siitä, että pellon hintamuutokset eivät ole Suomessa yhteydessä toteutuneisiin maatalouden kannattavuuden muutoksiin.

Hieman yllättävään tulokseen saattaa vaikuttaa se, että maataloudessa tapahtuneet muutokset eivät ole vaikuttaneet niinkään maataloustuloon, vaan maataloustulon kehitykseen liittyviin odotuksiin. Mallissa näitä odotuksia ei pystytty ottamaan huomioon. Odotukset ja epävarmuus ovat heijastuneet pellon hintoihin. Sattumalta samaan ajanjaksoon osunut yleinen talouslama ja pellon hintojen notkahdus korreloituvat kuitenkin aineistossa voimakkaasti. Mallin vahvuus on kuitenkin siinä, että maataloudesta pellon hintoihin tulevien vaikutusten muutosta pystyttiin tarkastelemaan yli ajan. Tässä vaikutuksessa ei havaittu suuria muutoksia. Tulos kertoo siitä, että pellon myymiseen ja hintoihin vaikuttavat tekijät ovat pysyvämpiä, kuin EU jäsenyyden kaltainen toimintaympäristön muutos.

Uudessa-Seelannissa maataloustulo ja yleinen talouskehitys ovat vaikuttaneet pitkällä aikavälillä 
keskimäärin yhtä suurella painolla pellon hintoihin. Kehityssuunta on kuitenkin ollut, että maataloustulon merkitys pellon hintoihin vaikuttavana tekijänä on laskenut. Kehitys onkin johtanut siihen, että maatalouden kannattavuus ja pellon hinnat ovat 50 vuoteen kauimpana toisistaan. Näitä havaintoja pidettiin maatalouden kannalta kestämättöminä ja erittäin huolestuttavina.

\section{Kirjallisuus}

Cuthbertson, K., Hall, S. \& Taylor, M. 1992. Applied Econometric Techniques. Philip Allan.

Engle, R. F. and Granger, C. W. 1987 "Co-integration and Error Correction: Representation, Estimation and Tersting” Econometrica 55:251-276.

Goodwin, B. K., Mishra, A. K., \& Ortalo-Magne, F. N. 2003. What's Wrong with Our Models of Agricultural Land Values. American Journal of Agricultural Economics 85(3). 744-752.

Haldane, A G \& Hall, S G. 1991. " Sterling's Relationship with the Dollar and the Deutschemark:1976-89," Economic Journal, Royal Economic Society, vol. 101(406), pages 436-43, May.

Hall, S G \& Robertson, D \& Wickens, M R, 1992. " Measuring Convergence of the Eu Economies," The Manchester School of Economic \& Social Studies ,Blackwell Publishing, vol. 60(0), pages 99-111.

Peltola, R. 1997. Maatalousmaan arvo ja hinta Suomessa v. 1980-1996. Maanmittauslaitoksen julkaisuja nro 83).

Peltola, R., Mattila, P. \& Kasteenpohja, E. 2006. Pellon arvo. Maanmittauslaitoksen julkaisuja nro 102. Maanmittauslaitos, Kehittämiskeskus 2006. 43 s. + liitteet 6 s.

Pyykkönen, P. 2006. Factors Affecting Farmland Prices In Finland. Pellervo Economic Research Institute Publication No. 19. 151. p.

Ylätalo, M. 1992. Lisäpellon tuotto- ja kauppa-arvon määrittämisen perusteet ja soveltuvuus pellon arvon osoittamiseen Etelä-Suomessa vuosina 1972-1986. Pellervon tal. tutk. lait. julkaisuja 11. 